Finally, we woxid notice an epidemic observed by Dr. and as it has been conceded that any chancre will ultimately Santlus, " at Hactanar, in 1853 ; and a similar attack at Werstersbourg, in 18x7. He has miscalled it croup. Its nature is very obviously diphtheritic _- " a white, creamy membrane occupied the whole of the pharynx." The interesting feature of this epidemic was that it was often accompanied at the commenceraent by a miliary exanthem, which appeared on the arms, clavicular region, and at the borders of the axilla. This has oceurred more than once in England; and this eruption has been commonly but erroneously described as that of irregular or suppressed scarlatina, with which it has nothing in common. In conclusion, we can only find space to mention the occurrence of a terrible epidemic of diphtheria at San Francisco, in the autumn of 1856 , which persisted through part of the following year. It had all the typical characters of pharyngeal diphtheria. Dr. J. V. Fourgeaudt has published a monograph on this epidemic. He describes the mortality amongst children, in several counties around the Bay of San Francisco, as having "assumed an appalling character." "Few children," he says, "attacked by it recovered." $\mathrm{He}$ placed his main reliance on muriatic acid as an agent for local cauterization, and, like Bretonneau, he had full reason to be satisfied with its action.

Amongst the most instructive deductions which may be obtained from the review of these various epidemics, is the observation of the identity of the disease preserved through many transformations of its seat and symptoms-attacking sometines the gums, especially at others the pharynx, soft palate, the larynx, and bronchial tubes, or the nasal fossæ. It preserves always the distinctive characters of diphtheritic or membranous inflammation, and calls for the same system of treatment. a specific in the third class where secondary symptoms do not follow. The author considered its value doubtful in the second class, phagedæena being rarely followed by those affections most benefited by mercury. Thus there only remained the first class, which probably comprised at the ntmost one. seventh of all the forms of chancre, showing that the great reputation mercury enjoyed was from its having been used in discriminately in cases where, perhaps, five or six times out of seven, no further affections would have followed. Even in the first class its value as a preventive was not certain, while its destructive properties were to be dreaded. According to the author's experience, its bad effects had principally been wit. nessed where it had been given in primary syphilis, or in the early stage of secondary disease; whereas, if employed later, it might be used to almost any extent. The course of chancres. gives the clue to their treatment: they all heal by suppuration. The use of caustic soda, irrigation two or three times daily, and water dressing, are, perhaps, as well calculated to procure quick healing as any of the hundreds of lotions ever invented, though phagedenic and indolent sores might occasionally require the use of a mild astringent and aromatic lotion. The indurated chancre healed under the use of mercury, iodide of potassium, or dilnte nitric acid; the suppurating chancre required little more than keeping the bowels open; phagedænie sores soon assumed a healthy appearance under the use of steel; rest, however, and opium were often necessary in the more severe forms. Sloughing sores amended under the exhibition of morphia, ammonia, and ether. With regard to bubo, we had everything to gain by arresting its progress. The bubo, followed by secondary symptoms, was from the very first of a different class to that which was not succeeded by them. If the bubo did not naturally tend to become inoculable, the advent of secondary symptoms was neither arrested nor retarded, nor was the severity of these affections diminished by promot. ing suppuration. The same thing might be said of the two forms of phagedæna; allowing it to proceed nnchecked did not arrest the symptoms, for these only succeed to the softer form. The author recommended a light, unirritating diet, but no starvation; and, in conclusion, begged he might not be misunderstood. He did not counsel a non-mercurial treatment of syphilis: he simply sought to examine in what cases of primary syphilis it might be dispensed with.

In the course of the discussion which followed, several interest. ing points connected with the question of the bearing of syphilis were enlarged upon - such as the possibility of infection from a mere induration. Mr. Milton related three cases which had come under his notice in private practice, from which he was led to believe a modified form of infection might be conveyed by a person without any primary sore at the time. The question of the possibility of communicating the virus through diseased semen-whether affections of the tongue ap. peared without intervening eruptions, the unity of the syphilitic virus, and the positive relation that existed between en. largement of the cervical glands and secondary eruptions, received their share of attention. Mr. Milton concluded his reply by stating his conviction that true syphilis could often, if not al ways, be cured without mercury. everal classifications of Abernethy, Wallace, Skey, Guthrie, than, and Judd, which last had acknowledged no les nnsolved the two greatest problems-viz., the occasional nonoccurrence of secondary syphilis after chancre, and the separation of those sores in which mercury may be given from those in which it is totally unnecessary. With Ricord and Lee came a new era; and when inoculation came to be so practised as to familiarize men with its results, he believed syphilis would be divided into three classes:- -1 . The indurated chancre; those with little hardening and certain small follicular chancres followed by true secondary syphilis. 2. Soft phagedænic chancres, and some forms of soft chancre not followed by inoculable bubo, but succeeded by a certain kind of secondary affections. 3. Hard phagedænic chancres, sloughing chancres, and suppurating chancres, with inoculable bubo not followed by secondary symptoms. Until some division like this have been established he proposed that a system similar to that of $\mathrm{Mr}$. Lee should be adopted, and that the predominant form of action should be taken as the distinguishing mark. This would give four forms-the depositive or indurated, the suppurating, ulcerative, and sloughing sores. Now, one of the first points in treatment is to eliminate at the outset those cases which may require mercury from those in which it is inadmissible or unnecessary;

* Santlus : Epidemics of Croup.-Journal für Kinder krank, 1854

+ Diphtheria: a Concise, Historical, and Critical Essay on the late Pseudo. Membranous Sore-throat of Califurnia, 1856-7. Sacramento, 1858 .

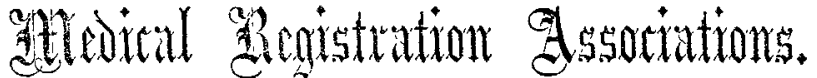

\section{THE LONDON MEDICAL REGISTRATION ASSOCIATION.}

Report and Proceedings of the Vigilance Committee.

THe General Committee met on Wednesday, the 5th inst., at the British Coffee House, 27, Cockspur-street, Charing-cross, when the "Vigilance Committee" brought up the following

REPORT.

"At the meeting on the 17th of December, 1858, your Committee had under consideration the present mode of registration, as adopted by the Registrar, and was of opinion that it was loose and inefficient, and not in accordance with Clause XV. of the new Medical Act. It was resolved that a deputation should wait upon Dr. Hawkins, for the purpose of confer. ring with him upon this important subject.

"On the 22nd of December, this Committee had an interview 
with Dr. Hawkins, there being present, Dr. Webster, President; Mr. Bottomley, Treasurer; Dr. Ladd, Hon. Sec.; Dr. Kirby, Dr. Thorn, Dr. Wright, Mr. W. Adams, and the Assistant. Secretary.

"Your Committee (having heard from Dr. Hawkins an explanation of the morle of registration pursued) recommended the adoption of a 'form' to be filled up by every person who wishes to become registered, declaring that his diploma had been lavfully obtained; that he is the person referred to and mentioned in the said diplomas, and that he is qualified to be registered under the new Medical Act; together with evidence of the possession and correctness of documents when the same are not produced before the Registrar. Some of these 'forms' were left with Dr. Hawkins.

"The Registrar having stated that he was entirely in the hands of the Executive Committee of the Branch Medical Council for England, your Committee deemed it necessary to put themselves in immediate communication with the Executive Committee of the Branch Medical Council, requesting an interview with that body, which they accordingly did by means of the following letter:-

\section{"To the Executive Committee of the Branch Medical Council of England.}

" "Gentremen, -On behalf of the Committee of the London Medical Registration Association, I beg to transmit to you a copy of the resolutions passed at a meeting of that body, held on December 22nd instant, subsequently to an interview with Dr. Hawkins, the Registrar under the new Medical Act, with reference to the mode of registration as at present conducted.

6" The Committee of the London Medical Registration Association are urgently anxious for the favour of an early inferview with the Executive Committee of the Branch Medical Council of England, for the purpose of explaining their reasons for having adopted those resolutions, and request that you will appoint an early day for that purpose.

I have the honour to be, Gentlemen,

(Signed, Your obedient servant,

Committee Room, British Coffee House

Cockspur-street, Charing-cross, Dec. 23rd, 1858

"6 ' Resolution 1st. - That this Committee having learnt from Dr. Hawkins, the Registrar of the Medical Council, the mode at present adopted for registering practitioners under the new Medical Act, declare their conviction that such mode is loose and inefficient, and does not afford an adequate security against fraudulent registration.

" "Resolution 2nd.-That as it is within the knowledge of this Committee that many persons are practising the medical profession with diplomas fraudulently obtained, and that as such persons may seek to be registered under the new Medical Act by virtue of such diplomas, this Committee would urge apon the Executive Committee of the Branch Medical Council the necessity of adopting a 'form' of declaration of qualifications to be used by all persons applying to be registered, and which should be duly attested by the signature of a credible witness, whereby persons obtaining registration by fraud would be amenable to Clause XXXIX. of the Act.'

${ }^{6}$ Your Committee have, through the Hon. Secretary, been in constant communication with Dr. Hawkins, who has been regula:ly informed of all the cases of anqualitied and doubtful persons submitted to them.

${ }_{6}^{6}$ Your Committee have much pleasure in announcing that practitioners in town and country are rapirly adopting the suggestions of your Committee, and are joining, and registering through the Association. This facility your Committee believe will be duly appreciated by the profession.

${ }^{66}$ Your Committee feel it most desirable that they should be in frequent communication wit in local Registration Associations, and would surgest for your sanction and approval, that such local Societies should be invited to co-operate with the Central (London) Association; and that the sum of $£ 1$ 1s. per annum be the minimum subserintion from each of such local Societies to the London Medical Registration Association."

This Report was unanimously adopted by the General Committee of the Association.

In consequence of no reply from the Executive Committee of the Branch Medical Council having been received previous to the meeting, it was, amongst other resolutions passed,--

Moved by Mr. BotTomex, seconded by Dr. KIRBy, and carried unanimously,

"That a protest against the present mode of registration under the Medical Act be forwarded to the President of the
Medical Council, signed by the President, Vice-Presidents, and members of the Committee of the London Medical Registration Association."

A Sub-Committee was accordingly appointed to draw up and forward the protest, which was as follows, and was forwarded accordingly:-

"To Sir Benjamin Brodie, Bart., F.R.S., D.C.L., dc., President of the Medical Council.

SIr, - As office-bearers and a Committee of the London Medical Registration Association, we beg most respectfully to call your attention to the plan of registration as at present adopted by the Registrar, Dr. Francis Hawkins, and we are induced to do so because we feel that the profession to which we belong is in peril of being deprived of the boon which the recent Medical Act undoubtedly confers on it, by the inefficient and unsatisfactory manner in which the provisions of the Act relating to registration are put into practice. The Association which we have the honour to represent, perceives, with much concern and regret, that the instructions given to the Registrar by the Executive Committee of the Medical Council do not re quire him to pursue a mode of registration sufficiently stringent to prevent unqualified persons from enrolling themselves on the register, and thereby usurping the privileges of duly-qualified medical practitioners. All that has been hitherto required for registration consists in the payment of a fee, and the hand. ing in a name which appears on one or other of the 'certified lists.' Any production of the documents conferring the qualifications professed, evidence of the lawful possession of these, or proofs of identity, are deemed unnecessary, the exception being thus followed rather than the rule prescribed by Clause $X V$. of the Medical Act. We therefore feel it incumbent upon us to protest against a course which is so palpably inefficient and open to abuse.

A deputation from our Association waited on Dr. Hawkins on the 22nd ultimo, and on learning from him that he was acting under the directions of the Executive Committee, we communicated by letter with that body, but not having received their reply, we address ourselves to you as President of the Medical Council, in the full assurance that you will not disregard so strong an expression of opinion from your medical brethren, on a subject which so materially affects their interests. We earnestly hope that you will, without delay, use your in. fluence to improve the present system of registration, which must result in the publication of an inaccurate and incomplete register, alike injurious to the public and the profession. Before closing this communication, we think it right to express it as our opinion, that it is essential to registration that the Registrar should, in the case of every applicant, require a simple form of declaration, to be signed to the effect, that he is (or has been) lawfully possessed of the document of the qualification which he claims to register, and that he is the person mentioned in the document or documents evidencing his qualification; this declaration to be attested by the Registrar, or some credible witness. Such a plan, we believe, will be both simple and effectual, and will not impose an irksome task on the qualified members of our profession, while it will deter unqualified persons from attempting to register by bringing them within the severest penalty of the Act, as provided by Clause XXXIX. We respectfully enclose a copy of a form which appears to us to be suitable for the purpose. A waiting your reply, We have the honour to remain, Sir, Your very obedient servants,

Geo. Webster, M.D., President. JoHN BRADY, JoHN LAVIES,

JoHN Propert, ThEod. E. LADD, M.D., Hon. Secretary. WrLLIAM ADAMS,

RobT. Cross, M.D. Charles Day, E. A. KTREY, M.D., MATTHEW LEDGER,

WM. ThorN, M.D. H. G. WRight, M.D.,

Members of the Committee of the London Medical Registration Association.

Committee Ronm, British Coffee House,

A large number of members were elected at this meeting of the Association, and it may be added that Mr. Fergusson has become one of its Vice-Presidents.

At a meeting of the Vigilance Committee, held on Wednesday last, the following communications were read:- 
" 18 , Bolton-street, W., Jan. 7th, 1859.

SIR,-I am directed by the Executive Committee of the General Council of Medical Education and Registration of the United Kingdom, to request that you would inform the committee of the London Medical Registration Association that they have received and considered the resolutions passed by the committee of the Association on the 22nd ult., and that they shall always feel obliged for any information or assistance that the committee of the Association may be disposed to lend them for the purpose of ensuring the correctness of the Register, but that they see no reason for a personal interview at present. I am, Sir, your obedient servant,

Theodore E. Ladd, M.D., Hon. Sec." FRANCIS HAwKINs, Registrar.

"14, Savile-row, Jan. 10th, 1859.

MY DEAP SIR, - I will take care that your suggestions are duly considered by the Executive Committee. The matter of registration is attended with much difficulty, and requires the greatest circumspection, and, therefore, cannot be carried out so rapidly as the profession may have expected. In the meanwhile you may be assured that the Registrar will be glad to have all the help which others can afford him in performing the duty which he has undertaken. If I am not mistaken, the Registrar mentioned to the Executive Committee an oral communication that he had had from you and some of your friends on the subject, and they agreed that it was desirable that all such communications should be in writing, in order that they might have the opportunity of discussing them without danger of misunderstanding them.

Dr. Webster." I am, Sir, yours very truly,

B. C. Brovie.

It was moved by Dr. Cross, seconded by Mr. DAY, and carried unanimously, - " That these communications be laid before the General Committee of the Association at their next meeting."

\section{TUNBRIDGE WELLS MEDICAL REGISTRATION} ASSOCIATTON.

A MEETING of the members of the South-Eastern Branch of the British Medical Association, and other members of the medical profession, was held on Saturday last, at the Royal Sussex Hotel, Tunbridge Wells, for the purpose of forming a Registration Association for that place and neighbourhood; Mr. Righton Gream in the chair. The minutes of the general meeting held at Brighton on the 18th of December last, appointing Mr. Trustram secretary, and prescribing the limits of the district, having been read, and the Chairman having explained the objects of the meeting, and read letters from gentlemen wishing to become members, the following resolutions passed at the general meeting were read:-

"That the secretary in each district be requested to call a meeting of the members resident therein, to which meeting all qualified members of the profession resident within the district should be invited.

"That the district secretaries should be at liberty to call a meeting of the Registration Committees whenever necessary.

"That each district should choose a sub-committee annually, and report such choice at the annual meeting of the Branch.

"That the expenses of the committees be defrayed by the treasurer of the Branch, provided they do not exceed l $s$. for each member; and that gentlemen not members of the Association joining the committees for registration should pay

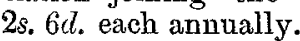

"That the secretaries be appointed until the annual meeting in 1860 , and afterwards yearly at each annual meeting.

"That it shall be the office of the committees to communicate with the Medical Registrar with regard to any improper or irregular registration - to consider and take any steps that may be necessary with regard to any contravention of the Medical Act, and to assist the Registrar in obtaining as perfect a registry as possible of the profession in each district."

Mr. Trusteam proceeded to observe that, as the time had now arrived when the public would have the advantage of distinguishing the legitimate practitioners of the healing art from those pretenders who had at all times infested the ranks of the profession, and as they themselves would have the opportunity of knowing the source from which all and every one of its mem. bers derived their qualifications, declared under a penalty sufficiently great to prevent fraud, it would have been surprising if that opportunity had been treated with indifference. Some of those gentlemen who had consented to join them, and had ex- pressed fears lest their proceedings mightbe considered more than uperfluous, even obtrusive, certainly need no lonyer entertain uch fears; for the Registrar himself had acknowledged the usefulness, and even courted the assistance, of such Associations. Some Associations he saw were assisting in the registration of he members in their localities; but this appeared unnecessary in so small a district as their own, where everybody was within reach of a post-office order. The important feature of the Association would be, that it offered to its members the opportunity of bringing under its notice any instances of unqualified practice, and thereby preventing personal altercation or responsibility. In this neighbourhood they had been freer from quackery than most others. There was no telling how soon their turn might come; but there was no question that the existence of an Association, which undertook to bring all such matters before the notice of the Registrar, wonld act as a terror to evil-doers.

The following resolutions were then passed :-

1. "That in the opinion of this meeting it is desirable to form a Registration Association for this place and neighbourhood as nearly as possible as prescribed by the resolutions of the general meeting."

2. "That this meeting adopts the resolutions of the general meeting, reserving to the committee now appointed the power to modify them, so as to meet any particular requirements of the disirict."

3. "That ten gentlemen, with the chairman and secretary, be the committee, with power to add to their number: three to be a quorum."

4. "That the committee do assist in the registration of any of its members, if required."

5. "That it shall be the duty of the committee to attend to any information that may be forwarded to it by any of the members of this Association, bearing on the sixth resolution of the general meeting, in order to prevent the necessity of any personal feeling in the operation of the Act."

6. " That it shall be the duty of all members of this Association to forward to the committee any facts bearing on any fraudulent qualification, and any instances of practice by un. qualified persons."

After a vote of thanks to the chairman and secretary, the meeting terminated.

North Staffordshire Mrdical Registration Assoctarion. - At a meeting of the medical practitioners of North Staffordshire, held at the Railway Hotel, Stoke-upon-Trent, on the 5th inst., the following resolntions were adopted:Moved by Mr. TuRnER, seconded by Dr. HAILAM,_" That an Association be formed for the purpose of aiding in carrying out the provisions of the new Medical Act; and that such Association be called the North Staffordshire Medical Association." Moved by Mr. HoLTom, seconded by Mr. Boothroyd, "That all legally-qualified medical practitioners, resident in North Staffordshire, be eligible as members of this Association." Moved by Mr. Elinington, seconded by Mr. Trourbeck, "That every member of this Association shall, on admission, pay an entrance fee of $2 s .6 d$." Moved by Mr. Yates, seconded by Mr. TURNER, - " That a committee be appointed, with power to add to their number, to carry out the objects of the Registration Association." Moved by Dr. WILson Fox, seconded by Mr. HoLtom,_- "That the duties of the committee shall be to communicate with and assist the Registral appointed by the Medical Council in the performance of his duties, both with regard to the enrolling of properly-qualified practitioners and the exclusion of unqualified persons from the register; and to watch over all points connected with the interests of the profession in connexion with the Medical Act." It was unanimously resolved,_" That $\mathrm{Mr}$. Yates be appointed Trea. surer and Honorary Secretary."

Chichester Medical Registration Committey. - At a meeting of the legally-qualified medical practitioners of West Sussex, held at the Council-chamber, Chichester, on Thursday the 6 th instant-Dr. M'Carogher in the chair, - the following resolutions were unanimously adopted:-1. That a committee be formed, and named the "Chichester Medical Registration Committee," in connexion with the South-Eastern Branch of the British Medical Association (as proposed at a meeting of that body, held at Brighton, on Dec, 3rd, 1858), and in accordance with rules then agreed upon. 2. That Mr. C. S. Jones: surgeon, of Chichester, be appointed secretary and treasurer of the committee. 3. That the object of the committee be to assist the Medical Registrar in effectually carrying out the 